\title{
A agroecologia propiciando o acesso a mercados para pequenos produtores rurais: o caso do Centro Sabiá
}

Agroecology providing access to markets for small rural producers: the case of Centro Sabiá

Agroecología brindando acceso a mercados para pequeños productores rurales: el caso de Centro

Sabiá

Recebido: 13/01/2021 | Revisado: 14/01/2021 | Aceito: 20/01/2021 | Publicado: 24/01/2021

\author{
Bárbara Denise Ferreira Gonçalves \\ ORCID: https://orcid.org/0000-0001-7712-7817 \\ Universidade Federal de Campina Grande, Brasil \\ E-mail: goncalvesbdf@gmail.com \\ Isabel Lausanne Fontgalland \\ ORCID: https://orcid.org/0000-0002-0087-2840 \\ Universidade Federal de Campina Grande, Brasil \\ E-mail: isabelfontgalland@gmail.com
}

\begin{abstract}
Resumo
Ao questionar uma das maiores dificuldades enfrentadas pela população rural na região do Semiárido brasileiro, podese dizer que o maior desafio diz respeito aos períodos prolongados de escassez hídrica na região, à aridez do clima e à presença de solos pobres em matéria orgânica, desafios estes, que para serem enfrentados carecem de alternativas associadas a formas sustentáveis de gestão dos recursos naturais. Neste contexto, a produção agroecológica incorre em uma relação direta com as práticas realizadas pela população rural cuja ocupação principal da força de trabalho é a agropecuária, ao passo em que propicia condições do pequeno produtor rural de ter acesso a mercados locais e, a partir disso, alcançar uma melhoria de qualidade de vida. Diante de tais questões, o presente trabalho teve por objetivo realizar um estudo sobre projetos de natureza ambiental e de caráter sustentável realizados no meio rural, no Sertão do Pajeú, e que são norteados por práticas agroecológicas, almejando assim, verificar como esses projetos têm transformado contextos sociais no campo. Para tanto, o presente trabalho procedeu com a identificação de um conjunto rico e distinto de Programas que atuam no segmento da agroecologia. Foram identificados um conjunto de aspectos responsáveis por potencializar a transição do modelo convencional de agricultura para a produção agroecológica, a qual tem potencializado o acesso de pequenos produtores rurais a mercados locais e à geração de renda, melhorando assim, a qualidade de suas vidas.
\end{abstract}

Palavras-chave: Agricultura sustentável; Programas rurais; Qualidade de vida.

\begin{abstract}
When questioning one of the greatest difficulties faced by the rural population in the Brazilian semi-arid region, it can be said that the biggest challenge concerns the prolonged periods of water scarcity in the region, the aridity of the climate and the presence of soils poor in organic matter, challenges these, which to be faced, lack alternatives associated with sustainable forms of management of natural resources. In this context, agroecological production incurs a direct relationship with the practices carried out by the rural population whose main occupation of the workforce is agriculture, while providing conditions for the small rural producer to have access to local markets and, from there, achieve an improvement in quality of life. In the face of such issues, the present study aimed to carry out a study on projects of an environmental nature and of a sustainable character carried out in rural areas, in the Sertão do Pajeú, and which are guided by agro-ecological practices, aiming to verify how these projects have transformed social contexts in the countryside. To this end, the present work proceeded with the identification of a rich and distinct set of projects that operate in the segment of agroecology. A number of aspects were identified that are responsible for enhancing the transition from the traditional model of agriculture to the model of agroecological production, which has enhanced the access of small rural producers to local markets and the generation of income, thus improving the quality of their lives.
\end{abstract}

Keywords: Agriculture sustainable; Programs rural; Quality of life.

\section{Resumen}

Al cuestionar una de las mayores dificultades que enfrenta la población rural en el semiárido brasileño, se puede decir que el mayor desafío se refiere a los períodos prolongados de escasez de agua en la región, la aridez del clima y la presencia de suelos pobres en materia orgánica, desafíos estos, que a enfrentar, carecen de alternativas asociadas a 
formas sustentables de manejo de los recursos naturales. En este contexto, la producción agroecológica incurre en una relación directa con las prácticas que realiza la población rural cuya principal ocupación de la mano de obra es la agricultura, al tiempo que brinda condiciones para que el pequeño productor rural tenga acceso a los mercados locales y, a partir de ahí, lograr una mejora en la calidad de vida. Ante tales cuestiones, el presente estudio tuvo como objetivo realizar un estudio sobre proyectos de carácter ambiental y de carácter sostenible realizados en zonas rurales, en el Sertão do Pajeú, y que se guían por prácticas agroecológicas, con el objetivo de verificar cómo estos proyectos se han transformado. contextos sociales en el campo. Para ello, el presente trabajo procedió con la identificación de un conjunto rico y diferenciado de Programas que trabajan en el segmento de la agroecología. Se identificaron un conjunto de aspectos responsables de potenciar la transición del modelo agrícola convencional a la producción agroecológica, lo que ha mejorado el acceso de los pequeños productores rurales a los mercados locales y la generación de ingresos, mejorando así la calidad de sus vidas.

Palabras clave: Agricultura sostenible; Programas rurales; Calidad de vida.

\section{Introdução}

Desde os primórdios da história grande parte da humanidade vem utilizando os recursos naturais de forma predatória e sem preocupação com a sua conservação. Segundo Vieira (2019), particularmente ao longo dos dois últimos séculos, impactos cada vez mais violentos vêm sendo provocados sobre o meio ambiente e desde o início do século XX essa conjuntura constituiu um cenário potencializado de ações antrópicas sincronicamente com quadros de injustiça social.

Quando o que se aborda é a superexploração dos recursos renováveis e as consequências sobre o meio ambiente, pode-se considerar que as incertezas e as irreversibilidades nas dinâmicas dos sistemas nos fazem repensar sobre um novo desenvolvimento que seja viável. Os valores presentes nos sistemas sociais e no interior dos grupos que o integram produzem uma representação da natureza, o que significa dizer que nossa compreensão sobre a preservação do meio ambiente precisa ser construída dentro de uma perspectiva das relações nas sociedades (Weber, 1997).

Notadamente aos sistemas produtivos na agricultura, Vieira (2019) dá ênfase ao quanto o meio rural é marcado por problemas de injustiça estruturais para com os pequenos agricultores e quando muitos deles têm dificuldades de produzir, em comparação aos agricultores mais capitalizados, cabe repensar a importância de práticas prudentes no meio rural que protejam o meio ambiente, viabilizem a formação de um tecido social que seja cooperativo e proporcionem melhoria da qualidade de vida.

Em vista da necessidade de mudança de paradigma relacionada ao modo de uso dos recursos naturais, surgiu uma maior preocupação com a produção limpa de alimentos. À vista disso, a busca de um modo de produção alternativo e mais eficiente para os produtores rurais tornou-se primordial para a aplicação de práticas menos degradantes e com potencial de promover a preservação máxima dos recursos naturais, conjuntamente a melhores condições de produção agrícola viabilizando, então, a geração de renda baseada em práticas mais sustentáveis (Barros, 2010).

É nesse contexto que as práticas agroecológicas, as quais apresentam bases científicas de transição da agricultura convencional para uma agricultura sustentável, apresenta-se com uma série de princípios e metodologias que propõem alternativas para minimizar a artificialização do ambiente natural pela agricultura. Não obstante, tendo como princípio prioritário a conservação e a ampliação da biodiversidade dos sistemas agrícolas como base para produzir sustentabilidade (Assis, 2006).

Diante de tais aspectos aqui expostos, o presente trabalho teve por objetivo realizar um estudo sobre projetos e ações de natureza ambiental e de caráter sustentável realizados no meio rural, no Sertão do Pajeú, e que são norteados por práticas agroecológicas, almejando com isso, identificar o modo como esses projetos e ações têm transformado contextos sociais no campo, nessa região do semiárido brasileiro onde as condições naturais são intensificadas pela ação antrópica. Ademais, nesta região onde a principal atividade da população rural é a agropecuária, destaca-se a carência de práticas de produção mais sustentáveis e que dêem condições das famílias agricultoras, que habitam nesse espaço, de se desenvolverem com segurança e qualidade. 
Para além da ação antrópica associada às dificuldades impostas pelas condições naturais da região, segundo Ferreira (2016), o Sertão do Pajeú tem sido palco de grandes lutas dos movimentos sociais, face à negligencia histórica dos governos diante da necessidade dos agricultores e agricultoras de base familiar. Nessa conjuntura, aspectos como o fortalecimento da sociedade civil, da mobilização, envolvimento e capacitação das famílias, com uma proposta de educação processual, são visualizados com a capacidade de transformar a realidade dessa região, tanto no que se refere ao ambiente natural do território, quanto no que condiz à qualidade de vida da população que vive da agropecuária.

Apesar de todas as ações indiscriminadas contra o meio ambiente, numa outra perspectiva, nos últimos 20 anos a região vivenciou um processo de melhoria de suas vidas, estando parte desta melhoria relacionada à atuação de instituições, como organizações não governamentais, e atores sociais como pesquisadores e outros da sociedade civil organizada, que ajudam a desenvolver a agricultura familiar agroecológica através de ações de articulação e de convivência sustentável com o ecossistema do Semiárido através do uso eficiente e sustentável dos recursos naturais.

Para tanto, o presente trabalho procedeu com a identificação de um conjunto rico e distinto de projetos e ações que atuam no segmento da agroecologia, utilizam eficientemente os recursos naturais, possibilitam uma produtividade agrícola sustentável e condicionam a criação de atividades econômicas, as quais geram renda e melhoria da qualidade de vida para a população rural do Sertão do Pajeú.

\section{Fundamentação Teórica}

A impossibilidade de muitas agricultoras e agricultores avançarem economicamente está relacionada a aspectos comerciais e financeiros, consubstancializando-se, estes, como os maiores obstáculos para o desenvolvimento econômico da produção no campo. Por essa razão, dentre os principais problemas que os produtores rurais enfrentam, estes problemas são mais frequentes do que as próprias dificuldades produtivas (Ramos, 2007). Segundo o IBGE (2006), uma das origens desse problema é a incapacidade dos agricultores familiares em cumprir com as condições do mercado.

A complementar, de acordo com Pearce (2002), as variações que acontecem na economia, especificamente nas variáveis econômicas, mesmo que relativamente pequenas mas podem incidir em colapsos sobre os sistemas ecológicos, de modo que a continuidade dos sistemas ecológicos depende da construção de um sistema econômico consistente com o uso eficiente dos recursos e da energia.

Segundo Guanziroli e Cardim (2000), a agricultura familiar brasileira é uma entidade heterogênea na qual a diversidade social e cultural dos pequenos produtores define diferentes níveis de infraestrutura e condições de vida, não apenas entre as regiões, mas inclusive dentro de cada região. No entanto, ainda diante uma diversidade de realidades socioeconômicas e ambientais, a agricultura familiar conquistou uma função relevante na produção de alimentos sendo responsável por 70\% dos alimentos produzidos para consumo no Brasil.

Apesar da agricultura familiar executar uma função imprescindível na produção de alimentos do país, mas a venda de produtos agrícolas muitas vezes não gera uma renda suficiente para satisfazer as necessidades do pequeno produtor (Barros, 2010). E, quando o que se discute são formas de auxiliar o pequeno produtor rural em sua atividade no campo, Mattei (2005) ressalta que as políticas públicas que foram desenvolvidas para o combate à pobreza no campo são bastante recentes e, até o início de 1990, não havia nenhuma política pública com abrangência nacional que atendesse as necessidades específicas do agricultor familiar.

A este ponto, torna-se ainda mais compreensível a relação que se estabelece entre: (i) as dificuldades de produção que o pequeno agricultor enfrenta; (ii) as adversidades de se alcançar produtividade agrícola e; (iii) a consequente limitação em comercializar os produtos do campo. Todos esses fatores contribuem para dificultar e até mesmo impedir que o pequeno produtor se desenvolva economicamente, posto que existe uma barreira estrutural para que o mesmo ingresse no mercado. 
Ainda, este último fator incide negativamente sobre o acesso ao crédito. Por outras palavras, tais dificuldades refletem os aspectos comerciais e financeiros inicialmente alertados.

A Lei da Política Agrícola, número 8.171 de 17/01/1991, coloca a proteção do meio ambiente entre os seus objetivos e como um de seus instrumentos e, define que o poder público deve desenvolver programas de educação ambiental, fomentar a produção de mudas de espécies nativas, entre outros. Frente a isso, na década de 90 começou a ser implantado a mudança do processo de produção agrícola convencional para o processo de produção agroecológica. De acordo com Ortega (2007), a agricultura agroecológica surgiu como uma forma de tentar solucionar os problemas de degradação do meio ambiente adotando, para tanto, uma produção agrícola sustentável que atenda às necessidades das gerações futuras. Todavia, a falta de auxilio público e privado fez com que a proposta agroecológica buscasse apoio na própria localidade. Assim, o desenvolvimento dessa experiência inovadora constituiu uma rede de solidariedade que forneceu base para construção de capital social.

Diferentemente da agricultura convencional que busca uma produtividade máxima com a utilização intensa de insumos, para se obter grande retorno econômico em curto prazo através do aumento da produtividade e de eficiência, a agroecologia, segundo Leão (2010), visa um novo estilo de produção limpa de alimentos e, notadamente no Brasil, alguns agricultores estão utilizando práticas da agroecologia que está proporcionando uma nova perspectiva para a agricultura do país, onde os produtos gerados por meio de cultivo agroecológico estão ganhando espaço cada vez maior na população, em vista dos benefícios do plantio sem agrotóxicos.

Outro movimento de fácil observação é a criação de espaços particulares para a distribuição e venda destes produtos como as "feiras agroecológicas", através das quais as agricultoras e os agricultores, assessorados principalmente por organizações não governamentais e atendidos por políticas públicas, têm oportunidade de acesso a um modelo diferenciado das feiras livres convencionais, que são denominadas como feiras orgânicas ou espaços agroecológicos (Leão, 2010).

No nordeste brasileiro, estas experiências agroecológicas vêm aumentando com o passar do tempo e, por forte influência de trabalho de ONGs e dos movimentos sociais no campo, o processo de transição da agricultura convencional para agroecológica atende mais de 13 mil famílias de agricultores em 120 municípios de 29 territórios em nove estados brasileiros (Paranhos, 2007).

Como exemplo deste processo de mudança pode-se observar o caso da ONG Centro de Desenvolvimento Agroecológico Sabiá - Centro Sabiá, a qual trabalha há 27 anos, para promoção da agricultura familiar dentro dos princípios da agroecologia, desenvolvendo e multiplicando a Agricultura Agroflorestal, também conhecida como Agrofloresta ou Sistemas Agroflorestais e busca, através de diversos setores da sociedade civil, desenvolver uma agricultura familiar de base agroecológica e a cidadania.

\section{Metodologia}

A unidade de análise à qual a pesquisa direcionou-se é o Sertão do Pajeú, assim chamado devido a menção ao Rio Pajeú o qual, em uma das características intrínsecas à sua geografia, atravessa parte dos municípios que compõem o território, desvelando assim, uma relevância expressiva para a população dessa parte do semiárido brasileiro. Este espaço foi cenário de atividades agrícolas inapropriadas realizadas na região, com o uso intensivo de agrotóxicos e, há cerca de 20 anos, o mesmo é tido como uma referência no que condiz à transição da atividade agrícola tradicional para uma nova forma de realizar a agricultura, através dos princípios da agroecologia, os quais respeitam o meio ambiente usando eficientemente os recursos naturais, como também criam condições de melhoria de qualidade de vida a partir do acesso a mercados e da geração de renda.

A pesquisa configura-se como descritiva, a qual, segundo Gil (2008), descreve as características de uma determinada população (aqui tida como a população rural, notadamente os pequenos produtores), ou o estabelecimento de relações entre 
variáveis (aqui tratada a relação entre o segmento da agroecologia, projetos e ações, e melhoria da qualidade de vida) e, concomitantemente a isso, está relacionada ao uso de técnicas padronizadas de coleta de dados (aqui concretizada na realização de entrevista, ao Centro Sabiá, para a obtenção de dados primários, e dados secundários advindos de pesquisa documental como base em relatórios, estudos e diagnósticos de experiências no Sertão do Pajeú).

Em conformidade com Pereira et al., (2018), o método deste estudo de caso tem seu enfoque qualitativo à medida em que o mesmo descreve um determinado caso e ao passo em que também apresenta uma particularidade que o torna especial. Por outras palavras, com o propósito de identificar um conjunto de aspectos responsáveis por potencializar a transição do modelo convencional de agricultura para a produção agroecológica, o estudo de caso fundamentou-se em Programas que permitiram não apenas descobrir e descrever aspectos que têm potencializado o acesso de pequenos produtores rurais a mercados locais e à geração de renda, mas que também possibilitaram identificar mudanças efetivas a partir da participação social e da inserção nos mercados locais.

Em conformidade com o objetivo da pesquisa, posteriormente à coleta dos dados, iniciou-se a organização do material a fim de identificar o acervo que viria a subsidiar três quadros de pesquisa, sendo eles três eixos temáticos sobre: (i) a agroecologia; (ii) projetos e ações executados no segmento da agroecologia; (iii) e quesitos ligados à produtividade agrícola sustentável e à criação de atividades econômicas que, por sua vez, são imprescindíveis à identificação da melhoria da qualidade de vida para a população rural do Sertão do Pajeú.

A considerar a natureza da pesquisa, aplicou-se a análise do conteúdo, como o método de análise dos dados, o qual consiste em permitir ao pesquisador uma gama mais ampla de informações sobre o que está sendo pesquisado, complementando assim, o conjunto de dados levantados para o embasamento técnico científico da pesquisa (Gil, 2008).

\section{Resultados e Discussão}

À vista do objetivo aqui pautado, o conjunto de dados levantados no Centro Sabiá possibilitou identificar Programas executados no Sertão do Pajeú e que têm como eixo de ação a agroecologia, como também possibilitou identificar ações específicas que norteiam a execução dos mesmos e, especialmente, relações e articulações institucionais que condicionam a abrangência dos Programas.

Relativamente ao Centro Sabiá, é uma organização não governamental com sede no Recife, Pernambuco, fundada em 1993, que trabalha para promoção da agricultura familiar dentro dos princípios da agroecologia. Juridicamente é uma associação civil de direito privado sem finalidade econômica, de natureza técnico-ecológica e educacional. A mesma, desenvolve e multiplica a Agricultura Agroflorestal, também conhecida como Agrofloresta ou Sistemas Agroflorestais, e tem como missão o desafio de interagir com os diversos setores da sociedade civil, desenvolvendo ações inovadoras consubstancializadas através de Programas com enfoques variados, conforme ilustração da Figura 1. 
Figura 1. Programas executados no Sertão do Pajeú através do Centro Sabiá.

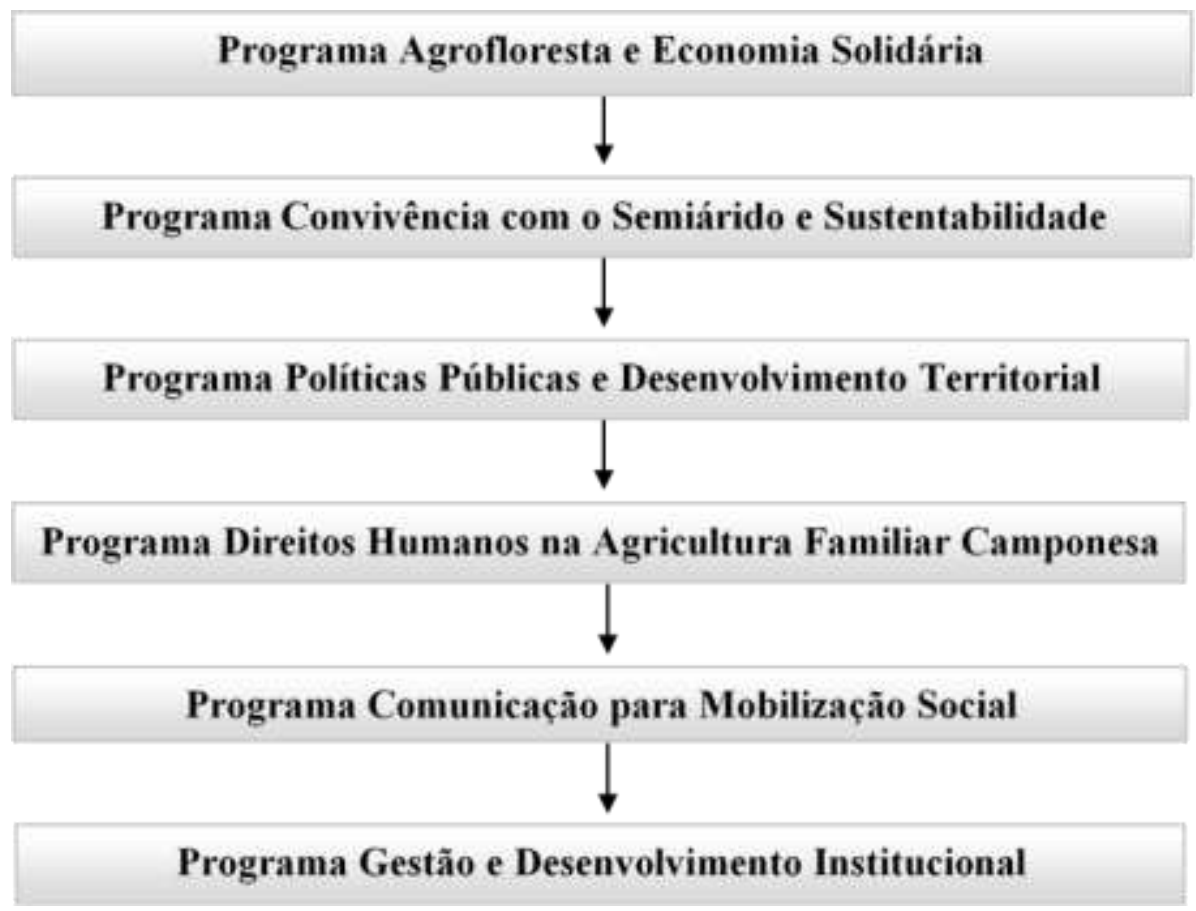

Fonte: Centro Sabiá (2020).

Isto posto, ressalta-se o Centro Sabiá pauta a sua ação através destes Programas cujos enfoques são variados e representam um contexto que engloba o âmbito social, ambiental e econômico e são realizados junto ao trabalho com crianças, jovens, mulheres e homens na agricultura familiar, na perspectiva de que a sociedade viva em harmonia com a natureza e seja consciente, autônoma e participativa na construção de um modelo de desenvolvimento rural sustentável.

De acordo com o Centro Sabiá, o modelo em que nossa sociedade vem se organizando nos últimos dois séculos revela um quadro de desigualdades e dificuldades que inúmeras famílias enfrentam. Notadamente na área rural, os Programas identificados têm como objetivo transformar a realidade dessa região que carece de ações de uso sustentável dos recursos naturais associadas à melhoria da qualidade de vida da população que reside nesse espaço. Adiante, a partir de descrições e de indicações quantitativas, é possível compreender a importância de atuação dos respectivos Programas.

\subsection{Programa Agrofloresta e Economia Solidária}

O fortalecimento da agroecologia é um grande objetivo do Centro Sabiá. Diante disso, o Programa Agrofloresta e Economia Solidária tem como propósito fortalecer a agroecologia, promovendo os sistemas agroflorestais como estratégia produtiva para a agricultura familiar camponesa, na perspectiva da soberania e segurança alimentar e nutricional, autonomia econômica solidária e o combate às desigualdades.

De acordo com dados originados da própria instituição, a estratégia dos sistemas agroflorestais como estratégia produtiva para a agricultura familiar e camponesa, já chegou a mais de 1.000 propriedades rurais em todo o Estado de Pernambuco e a atuação tem sido sempre na perspectiva da autonomia econômica solidária dos agricultores e agricultoras, da soberania e segurança alimentar e do combate às desigualdades. A seguir, o Quadro 1 apresenta informações do último relatório quantitativo de ações promovidas por esse Programa no ano 2018. 
Quadro 1. Ações geradas pelo Centro Sabiá através do Programa Agrofloresta e Economia Solidária.

\begin{tabular}{|c|c|}
\hline Ações específicas ao Programa & Quantitativo \\
\hline Famílias assessoradas em 27 municípios e 161 comunidades. & 1.030 \\
\hline Composição do público feminino nessas famílias. & $58 \%$ \\
\hline Jovens assessorados dos quais 60\% são jovens mulheres. & 468 \\
\hline Novos Sistemas Agroflorestais - SAFs implantados. & 50 \\
\hline $\begin{array}{c}\text { Casas de sementes em funcionamento nos territórios de atuação do Centro Sabiá } \\
\text { envolvendo 925 famílias agricultoras. }\end{array}$ & 44 \\
\hline Unidades de beneficiamento coletivas. & 8 \\
\hline Unidades de beneficiamento familiares em funcionamento no beneficiamento da produção. & 64 \\
\hline $\begin{array}{c}\text { Feiras Agroecológicas e da agricultura familiar em funcionamento com 217 famílias } \\
\text { agricultoras comercializando. }\end{array}$ & 12 \\
\hline $\begin{array}{c}\text { Visitas, reuniões e encontros com o tema de Acesso a Mercados tendo 1.009 participações } \\
\text { com 57\% de mulheres, sendo 87 atividades nas feiras agroecológicas. }\end{array}$ & 110 \\
\hline Grupo de Consumo Responsável em funcionamento. & 01 \\
\hline $\begin{array}{c}\text { Mudas de plantas medicinais, frutíferas, nativas, temperos e hortaliças distribuídas e } \\
1.103,250 \text { kg de equipamentos eletrônicos coletados para reciclagem na Campanha Mude } \\
\text { com Mudas. }\end{array}$ & 2.000 \\
\hline
\end{tabular}

Fonte: Centro Sabiá (2018).

Há 25 anos famílias agricultoras camponesas de Pernambuco experimentam e aperfeiçoam sistemas agroflorestais para produção de alimentos e, de acordo com Aureliano (2019), estas experiências demonstram que entre os sistemas agroecológicos, a agrofloresta é o mais resiliente e, quando exposta a uma determinada intempérie, como as secas, conseguem recuperar-se mais rapidamente demonstrando ser mais adaptada ao contexto de eventos climáticos extremos que estamos vivendo.

\subsection{Programa Convivência com o Semiárido e Sustentabilidade Ambiental}

Este programa busca oportunizar o desenvolvimento das ações de convivência com o ambiente para abrandamento e adaptação às mudanças climáticas, recuperação e manejo da agrobiodiversidade, uso das energias renováveis e direito aos bens comuns, tendo como base o trabalho das famílias agricultoras agroflorestais e outros sistemas agroecológicos. Destaca-se que o enfrentamento das mudanças climáticas é uma problemática que tem sido tratada com muita relevância no Centro Sabiá, de modo que, particularmente ao Programa Convivência com o Semiárido e Sustentabilidade Ambiental, buscou-se incrementar o desenvolvimento de ações para convivência com o ambiente.

À vista disso, as ações desse programa são norteadas por sistemas agroflorestais e tornam-se possíveis de execução devido ao trabalho das famílias agricultoras. Particularmente este programa tem tido êxito na implantação de cisternas de placas para garantir o acesso à água para famílias do semiárido.

Ao passo em que os sistemas agroflorestais são o fator chave de transformação do ambiente, os mesmos funcionam como uma estratégia aliada à recuperação e manejo da agrobiodiversidade, produção e uso das energias renováveis e acesso aos recursos naturais. Adiante, o Quadro 2 apresenta informações que expressam as formas de atuação através das quais o Programa é executado. 
Quadro 2. Ações geradas pelo Centro Sabiá através do Programa Convivência com o Semiárido e Sustentabilidade Ambiental.

\begin{tabular}{|c|c|}
\hline Ações específicas ao Programa & Quantitativo \\
\hline Tecnologias de captação de água da chuva, com capacidade de armazenamento de 24 \\
milhões de litros de água doce & 290 \\
\hline Sistemas de reuso de água cinza construídos e em funcionamento. & 50 \\
\hline Toneladas de forragem produzidas nos SAFs armazenadas. & 23 \\
\hline $\begin{array}{c}\text { Cursos de 24h cada, sobre manejo de água para produção de alimentos no semiárido com } \\
\text { 437 participações, sendo 73\% de mulheres. }\end{array}$ & 14 \\
\hline $\begin{array}{c}\text { Intercâmbios relacionados as temáticas de Convivência com o Semiárido e produção de } \\
\text { alimentos com 245 participantes, destes 70\% de mulheres. }\end{array}$ & 200 \\
\hline
\end{tabular}

Fonte: Centro Sabiá (2018).

De acordo com Pires (2019), mais de um milhão de cisternas já foram construídas e mais de cinco milhões de pessoas têm tido o acesso à água para beber e cozinhar, depreendendo a água como direito e com autonomia sobre sua gestão. Mas, no Semiárido ainda existem mais de 350 mil famílias sem água para o consumo básico e que ainda dependem da disposição política e da priorização por parte de prefeituras e governos estaduais. O custo para universalizar o acesso a água potável para famílias do Semiárido é definido em torno de R \$ 1,3 bilhão. Portanto, investir nessa política contribui para o alcance do $6^{\circ}$ Objetivo do Desenvolvimento Sustentável - Água Limpa e Saneamento, além de ser uma iniciativa de adaptação e mitigação dos efeitos das mudanças no clima.

Além das tecnologias de captação de água, em Pernambuco, os sistemas de reúso das águas de banho e lavagem de roupas irrigam plantações e mantêm criação de animais. De acordo com Genival Barros Junior, Professor de Agronomia da UFRPE de Serra Talhada, responsável por avaliar a eficiência do sistema de irrigação e a performance das culturas que estão recebendo as águas cinzas, a reutilização de águas cinzas não é nova na região e, a experiência com famílias do Sertão do Pajeú que vêm utilizando águas cinzas filtradas para irrigação adicional de agroflorestas, iniciada em 2018, tem trazido resultados relevantes, como mais uma esperança que se soma a tantas outras para a convivência no Semiárido concomitantemente a uma qualidade de vida viabilizada a partir da produção saudável e variada de alimentos e da promoção de uma economia solidária. Assim, a resiliência das famílias agricultoras do Semiárido, nos momentos de escassez de chuvas, aumenta consideravelmente quando optam pelas práticas agroecológicas em seus agroecossistemas.

\subsection{Programa Políticas Públicas e Desenvolvimento Territorial}

Segundo o Centro Sabiá, um dos mais importantes objetivos é a sua cooperação na elaboração de políticas públicas na ótica do fortalecimento da agricultura familiar e camponesa concomitantemente a um desenvolvimento territorial. Para tanto, a agroecologia é tida como um paradigma desse objetivo, ou seja, um modelo de referência que incentiva a organização dos agricultores e agricultoras em associações, sindicatos e cooperativas.

É notório o aspecto da interação, da parceria e da articulação que se estabelece, já não apenas entre famílias agricultoras, mas também entre outras instituições representativas das mesmas. Além disso, por ter o programa a característica peculiar de articulação, o mesmo é idealizado através de redes como a Articulação Nacional de Agroecologia, a Articulação Semiárido Brasileiro - ASA e a Rede Assistência Técnica e Extensão Rural - ATER Nordeste. Em conformidade com o Quadro 3, são identificadas ações específicas através das quais o Programa é executado: 
Quadro 3. Ações geradas pelo Centro Sabiá através do Programa Políticas Públicas e Desenvolvimento Territorial.

\begin{tabular}{|c|c|}
\hline Ações específicas ao Programa & Quantitativo \\
\hline Associações de agricultores/as assessoradas & 46 \\
\hline Educação Contextualizada. & 33 \\
\hline Escolas do campo com atividades de Educação Ambiental, Educação do Campo e & 339 \\
\hline Reuniões com Secretarias de Educação para planejamento de atividades em escolas do \\
campo. & 10 \\
\hline Reuniões e encontros das Redes Territoriais de Agroecologia. & 29 \\
\hline $\begin{array}{c}\text { Encontros preparatórios realizados em parceria com organizações de Pernambuco, } \\
\text { mobilizando uma delegação de 48 pessoas para o IV Encontro Nacional de Agroecologia. } \\
\text { Parceria do Centro Sabiá na construção do Curso de Bacharelado em Agroecologia da } \\
\text { UFRPE. }\end{array}$ & 03 \\
\hline $\begin{array}{c}\text { Reuniões, audiências públicas e encontros com FIDA, CNAPO, ALEPE, SEMAS, PCR, } \\
\text { ANATER, CPORG e EMBRAPA. }\end{array}$ & 15 \\
\hline $\begin{array}{c}\text { Redes e Comitês territoriais, regionais, nacionais e internacionais são espaços de } \\
\text { incidência política (Rede Espaço Agroecológico, RAMA, REAGRO, Rede Pajeú de } \\
\text { Agroecologia, Rede ATER NE, ASA, ANA, ABONG, PAD, Plataforma Semiáridos da } \\
\text { América Latina e Coalisão Internacional para a Terra; CNAPO e CPORg-PE). }\end{array}$ & 13 \\
\hline
\end{tabular}

Fonte: Centro Sabiá (2018).

A Misereor, obra episcopal da Igreja Católica da Alemanha comprometida, há mais de 50 anos, com a luta contra a pobreza na África, Ásia e América Latina, realizou estudos nestes três países e, de acordo com os estudos no semiárido do Brasil, constatou-se que os benefícios benfazejos aos mais pobres não surgem a partir de soluções tecnológicas rápidas, mas de uma orientação para a mudança de processos, capacidade, organização, apoio e práticas para agricultores e seu contexto sociopolítico.

Com base nestas experiências, foram propostas Recomendações Políticas que incorporam processos para gerar e preservar valores compartilhados de igualdade, solidariedade e justiça. Tais recomendações destacam a necessidade de um desenvolvimento rural eficaz focado na agroecologia, no qual, faz-se urgente a criação de políticas públicas moldadas por um desenvolvimento participativo. Assim, a partir de uma experiência internacional, cinco recomendações políticas foram dispostas, sendo elas as seguintes:

\section{Os Governos e outros financiadores do desenvolvimento devem investir na agroecologia para o} desenvolvimento rural, a segurança alimentar e a sustentabilidade: a agroecologia é uma abordagem de baixo custo que tem um potencial de ajudar a enfrentar as três vertentes da crise de má nutrição atual, que são a subnutrição, as deficiências de micronutrientes, e a obesidade e excesso de peso, além viabilizar a sobrevivência e prosperidade econômica de agricultores de pequena e média escala.

II. Os governos devem reforçar as medidas para o desenvolvimento e a manutenção de infraestruturas rurais (particularmente o acesso sustentável à água segura e potável) que terão efeitos multiplicadores positivos nas rendas agrícolas, na segurança alimentar, na saúde e no desenvolvimento rural: a água é um direito humano básico e um recurso essencial em áreas semiáridas. O trabalho e o apoio a sistemas de irrigação adequados e o acesso à água devem ser expandidos, com a disponibilização de mais fundos, apoio ao conhecimento e atenção às necessidades e restrições locais. 
III. Governos e cooperadores nacionais e internacionais devem criar e fortalecer espaços de participação política efetiva em que as iniciativas e propostas da sociedade civil influenciam diretamente as decisões políticas e as alocações orçamentárias: a partir de um estudo internacional constatou-se a importância de políticas públicas que promovam um ambiente favorável a iniciativas agroecológicas. Portanto, devem ser construídas novas estruturas políticas que fomentem o diálogo participativo e intersetorial e permitam desenvolver, implementar e monitorar políticas públicas eficazes de forma participativa.

IV. Os governos deveriam garantir a instituições locais para que as mesmas possam promover aprendizagem e intercâmbio horizontal sobre agroecologia: os relatos de problemas e visões para sua solução foram apresentados pelas bases e o apoio técnico seguiu as demandas locais. Esta abordagem deve ser ampliada a outros programas de extensão rural, os quais devem ser fortalecidos e devidamente financiados, a fim de transformar os serviços de extensão atualmente geridos de cima para baixo.

V. Os governos deveriam incentivar economias diversificadas e inclusivas: a agroecologia pode envolver trabalho intensivo, bem como ser benéfica economicamente, tendo portanto, o potencial de criar oportunidades favoráveis de emprego em áreas rurais. No entanto, os requisitos subjacentes a um progresso contínuo incluem condições de trabalho justas e o apoio a uma variedade de mercados para agricultores familiares. As economias inclusivas e sustentáveis requerem a eliminação de obstáculos políticos atuais e a implementação de apoios adequados.

\subsection{Programa Direitos Humanos na Agricultura Familiar Camponesa}

Este programa tem por objetivo contribuir para o empoderamento das mulheres, jovens, negros e negras, indígenas e LGBT's da Agricultura Familiar Camponesa na luta contra as desigualdades, na perspectiva do fortalecimento da agroecologia. Adiante, o Quadro 4 reflete a diversidade de ações realizadas a partir desse Programa.

Quadro 4. Ações geradas pelo Centro Sabiá através do Programa Direitos Humanos na Agricultura Familiar Camponesa.

\begin{tabular}{|c|c|}
\hline Ações específicas ao Programa & Quantitativo \\
\hline Público das atividades de formação do Centro Sabiá são mulheres, sendo 37\% mulheres \\
adultas e 18\% mulheres jovens. & $55 \%$ \\
\hline Público das atividades de formação do Centro Sabiá constituído por jovens. & $35 \%$ \\
\hline $\begin{array}{c}\text { Jovens participando ativamente de conselhos municipais, STR's, associações de } \\
\text { agricultores/as e também de redes e coletivos de juventudes. }\end{array}$ & 108 \\
\hline Jovens mobilizados e organizados em 17 grupos nas comunidades rurais. & 06 \\
\hline Atividades com a temática raça/etnia. & 07 \\
\hline Atividades com a temática da auto-organização das mulheres. & 25 \\
\hline Iniciativas de auto-organização das juventudes. & 130 \\
\hline
\end{tabular}

Fonte: Centro Sabiá (2018).

De acordo com Tubino (2013), a Agroecologia tem avançado no Brasil nos últimos anos, embora não seja possível comparar com o avanço do agronegócio, e um dos motivos desta expansão é o fato da Articulação Nacional de Agroecologia ter buscado novas alianças nos movimentos sociais.

A igualdade de gênero, geracional e étnica faz parte da representação desse contexto e é essencial para o fortalecimento da agricultura familiar e para a construção de uma sociedade mais igualitária. Fatores como a formação de mulheres, jovens, negros e negras, indígenas e LGBT's, a participação ativa de jovens, o desenvolvimento de atividades com a temática raça/etnia, têm sido razão de melhorias no tocante ao enfrentamento de barreiras e potenciais dificuldades 
relacionadas ao caráter produtivo da agricultura. O suporte institucional proporcionado pelo Centro Sabiá tem promovido o reforço à promoção da igualdade aos direitos humanos, com base na integração de uma perspectiva de gênero, nas suas ações, e relacionadas com as esferas da sociedade, moldando um novo quadro social que, no Brasil, ainda necessita progredir muito, inclusive em aspectos como oportunidade econômica e empoderamento político.

\subsection{Programa Comunicação para Mobilização Social}

Este programa objetiva, essencialmente, a formação dos sujeitos e o acesso à informação para mobilização da sociedade. Portanto, o Direito à Comunicação é visto como prioridade, especialmente para as famílias tantas vezes invisibilizadas no meio rural do nosso país. Isto posto, busca-se desenvolver um processo de comunicação para o fortalecimento da agricultura familiar e camponesa de base agroecológica.

Esse processo de comunicação é caracterizado por um método de construção do conhecimento o qual enseja a formação dos sujeitos e o acesso a informação, gerando assim, caminhos e condições para mobilização da sociedade. A seguir, o Quadro 5 apresenta as ações realizadas por este Programa:

Quadro 5. Ações geradas pelo Centro Sabiá através do Programa Comunicação para Mobilização Social.

\begin{tabular}{|c|c|}
\hline Ações específicas ao Programa & Quantitativo \\
\hline Edições de diferentes publicações impressas realizadas. & 05 \\
\hline Exemplares de edições de publicações impressas. & 19.650 \\
\hline Audiovisual produzido. & 01 \\
\hline $\begin{array}{l}\text { Participações institucionais em redes e fóruns pelo direito à comunicação (Fórum } \\
\text { Permanente pelo Direito à Comunicação - FOPECOM, } \\
\text { Rede de Comunicadores/as da ANA, Rede de Comunicadores/as da ASA-PE). }\end{array}$ & 03 \\
\hline $\begin{array}{l}\text { Oficina sobre mídias sociais com jovens da Comissão de Jovens Mobilizadores da } \\
\text { Agroecologia - CJMA realizada. }\end{array}$ & 01 \\
\hline Produtos impressos: Jornal Dois Dedos de Prosa & $\begin{array}{c}10.000 \\
\text { exemplares }\end{array}$ \\
\hline Produtos impressos: Agenda da Parceria & $\begin{array}{c}6.000 \\
\text { exemplares }\end{array}$ \\
\hline $\begin{array}{c}\text { Produtos impressos: Calendário Institucional Anual (parceria com o Centro de Assessoria } \\
\text { e Apoio a Trabalhadores/as e Instituições Não Governamentais Alternativas - } \\
\text { CAATINGA). }\end{array}$ & $\begin{array}{c}3.000 \\
\text { exemplares }\end{array}$ \\
\hline Produtos impressos: Cartaz "Não quero mais a Fome no meu país" & 650 exemplares \\
\hline
\end{tabular}

Fonte: Centro Sabiá (2018).

Somente em uma sociedade na qual os cidadãos têm o direito e o acesso à formação do conhecimento, é que se pode criar uma base de pessoas mobilizadas para, juntas, refletirem os problemas e pensarem soluções. À vista disso, segundo o acervo de materiais disponibilizados pelo Centro Sabiá, a soma de muitos deles, com destaque ao relatório da Misereor, no que condiz ao impacto de intervenções agroecológicas em regiões semiáridas de três países, nomeadamente, o estado de Pernambuco, no Brasil; o distrito de Fatick, no Senegal; e o distrito de Osmanabad, na Índia, fornece resultados robustos do impacto e potencial da agroecologia como a resposta para uma agricultura e sistemas alimentares mais sustentáveis.

Foi através de muitas discussões e na percepção crescente da necessidade de um foco agroecológico entre acadêmicos, a sociedade civil, as ONGs e organizações internacionais que defendem um futuro da alimentação diferente, mais sustentável e 
justo que, de acordo com o presente relatório, concluíram que as dificuldades e as limitações decorrem de processos biofísicos que surgiram a partir da tomada de decisões baseadas em curto prazo, desequilíbrios de poder e controle corporativo excessivo sobre os sistemas alimentares. Num planeta onde as taxas de insegurança alimentar e má nutrição são alarmantes, compreendese que se trata de uma problemática associada às crises de perda da biodiversidade.

É nesta conjuntura que cabe reconhecer que o desenvolvimento da agricultura está diretamente relacionado ao processo de formação do conhecimento e, em conformidade com o que Weber (1997) mencionou, com uma compreensão sobre a preservação do meio construída dentro de uma perspectiva das relações nas sociedades, a partir do qual a agricultora e o agricultor construirão bases para entender a importância das técnicas e do meio técnico no processo de construção de uma sociedade mais justa, na qual, eles e os seus filhos poderão constituir relações sociais democráticas e solidárias.

\subsection{Programa Gestão e Desenvolvimento Institucional}

Alcançar o êxito no tocante ao desenvolvimento e à multiplicação da Agricultura Agroflorestal, bem como o êxito no que concerne ao desafio de interagir com os diversos setores da sociedade civil, exige um constante aperfeiçoamento a fim de que se possa alcançar o crescimento institucional em bases sustentáveis e, com isso, conduzir as práticas e a atuação segundo a missão. Por essa razão, o Programa Gestão e Desenvolvimento Institucional desenvolve capacidades e aperfeiçoa as habilidades da equipe do Centro Sabiá, e também os mecanismos e instrumentos de gestão, praticando a democracia e a ética na captação, no uso de recursos e nas relações institucionais. Prioritariamente, o que se busca com este Programa é fortalecer a construção do sentido político de seu trabalho junto às famílias agricultoras. Abaixo, o Quadro 6 expõe ações de aperfeiçoamento geradas pelo Centro Sabiá a partir do Programa em questão:

Quadro 6. Ações geradas pelo Centro Sabiá através do Programa Gestão e Desenvolvimento Institucional.

\begin{tabular}{|c|c|}
\hline Ações específicas ao Programa & Quantitativo \\
\hline $\begin{array}{c}\text { Oficinas de assessoria em Captação de Recursos realizadas em parceria com o Centro de } \\
\text { Assessoria e Apoio à Iniciativas Sociais - CAIS. }\end{array}$ & 02 \\
\hline $\begin{array}{c}\text { Reuniões/encontros realizados para Monitoramento e Avaliação das açõe.s entre a } \\
\text { Coordenação Colegiada e a equipe com 340 participações. }\end{array}$ & 41 \\
\hline $\begin{array}{c}\text { Atividades realizadas para mobilização de recurso: reuniões, Encontros, levantamentos e } \\
\text { sondagens de novos parceiros. }\end{array}$ & 16 \\
\hline Projetos elaborados, dentre os quais 03 projetos aprovados. & 06 \\
\hline $\begin{array}{c}\text { Pessoas da equipe capacitadas nas temáticas de Raça e Etnia, Sistemas Agroflorestais e } \\
\text { ATER. }\end{array}$ & 16 \\
\hline $\begin{array}{c}\text { Reuniões e encontros realizados com redes, parceiros e espaços de articulação como ASA, } \\
\text { ANA, Rede ATER Nordeste, Plataforma Semiáridos, ABONG, PAD, Universidades } \\
\text { Federais, Rede Espaço Agroecológico, Diaconia, EQUIP, Campo Unitário e MST; } \\
\text { Participação ativa em 5 grandes Encontros/Caravanas: IV Encontro Nacional de } \\
\text { Agroecologia, Fórum Social Mundial, Fórum Alternativo da Água, Encontro Regional de } \\
\text { Agroecologia, Encontro Estadual de Agroecologia e Caravana Semiárido Contra a Fome. }\end{array}$ & 110 \\
\hline
\end{tabular}

Fonte: Centro Sabiá (2018).

\section{Resultados, frutos e multiplicações dos Programas Institucionais}

Segundo o Centro Sabiá, no ano 2018, em que o Brasil teve dados que condicionaram sua volta ao Mapa da Fome, de onde saiu em 2014, a ONG se movimentou para denunciar à sociedade o resultado dos sucessivos cortes orçamentários em 
políticas e programas de segurança alimentar, segurança hídrica e apoio à agricultura familiar. Assim, de acordo com o mesmo, em vista do propósito institucional de, através da promoção da agroecologia superar a fome das populações do campo, muitas transformações positivas já foram realizadas no que condiz à melhoria da qualidade de vida da população rural do Sertão do Pajeú, atuando na agricultura camponesa agroecológica para produção de alimentos, e não somente para o campo, mas também para a cidade, fator este que impulsionou o acesso dos pequenos produtores rurais ao mercado.

É impactante e reveladora a menção feita pela Organizações das Nações Unidas para Alimentação e Agricultura FAO, a qual reconheceu que a agroecologia é o caminho para acabar com a fome preservando a biodiversidade e os recursos naturais. Em associação a isso, constatou-se que o Centro Sabiá possui uma parceria de nível internacional, a qual enriquece a abrangência das ações realizadas no Pajeú, a partir de experiências mundiais. Esta informação é muito relevante à discussão, pois, particularmente à Agência de Cooperação Misereor, com a qual o Centro Sabiá possui parceria no semiárido pernambucano, foi constatado que a agricultura agroecológica produz mais alimentos e em maior diversidade que a agricultura não agroecológica.

Segundo estes dados, as famílias agroecológicas chegam a produzir até 1,5 toneladas de alimento por ha/ano enquanto as não agroecológicas não chegam a 1 tonelada/ha/ano. Isso significa que, por ano, as famílias agroecológicas consomem 600 $\mathrm{kg}$ a mais de sua própria produção de alimentos, o que garante a sua segurança alimentar a um menor custo e com muito mais qualidade. A complementar, quando o que se busca são práticas sustentáveis na agricultura que utilizam pouco ou nenhum insumo externo, que respeitam o meio ambiente, e que proporcionam melhoria da qualidade de vida, outro ponto também é evidente e refere-se à diversidade, isto é, o número de espécies existentes nas áreas das famílias agroecológicas é o dobro das não agroecológicas. Para além dessas notas, os resultados obtidos a partir dos programas institucionais mostram que os sistemas agroecológicos são mais adequados ao clima semiárido, pois se adequam melhor aos períodos de seca e às condições peculiares da região.

\section{Redes de Articulação do Centro Sabiá}

O Centro Sabiá está articulado com muitas outras instituições com as quais estabelece três relações, sendo elas a relação de ligação, a relação de participação e a relação de filiação. Destarte, o Quadro 7 identifica o conjunto de instituições que constituem essa articulação, a qual desvela uma riqueza de nível organizacional e uma estrutura bem definida: 
Quadro 7. Redes de Articulação do Centro Sabiá.

\begin{tabular}{|c|c|}
\hline RELAÇÃO & INSTITUIÇÕES \\
\hline LIGAÇÃO & 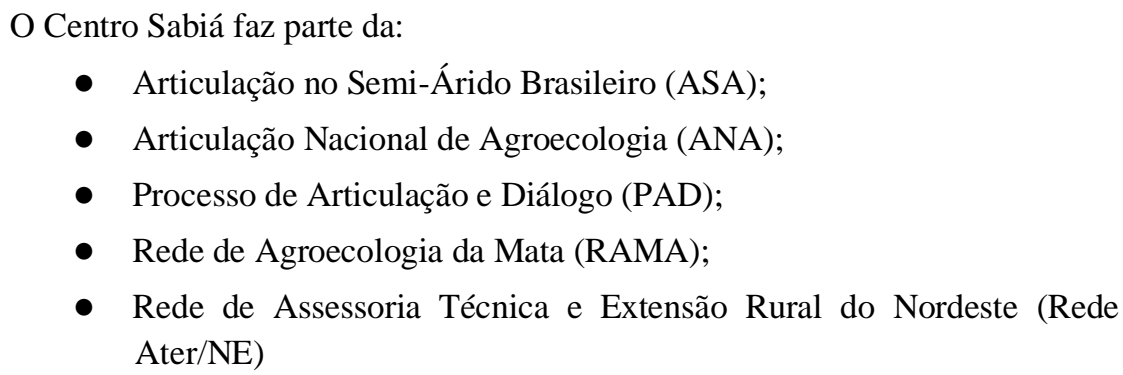 \\
\hline PARTICIPAÇÃO & $\begin{array}{l}\text { O Centro Sabiá participa dos seguintes espaços institucionais: } \\
\text { - Comitê de Ater do Conselho Estadual de Segurança Alimentar de } \\
\text { Pernambuco (Consea/PE); } \\
\text { - Conselho Nacional de Desenvolvimento Rural Sustentável (Condraf); } \\
\text { - Comissão da Produção Orgânica no Estado de Pernambuco (CPOrg- } \\
\text { PE); } \\
\text { - Colegiado do Território da Cidadania da Mata Sul. }\end{array}$ \\
\hline FILIAÇÃO & $\begin{array}{l}\text { O Centro Sabiá é filiado a: } \\
\text { - Associação Brasileira de Organizações não Governamentais } \\
\text { (ABONG). }\end{array}$ \\
\hline
\end{tabular}

Fonte: Centro Sabiá (2018).

\section{Feiras Agroecológicas do Centro Sabiá}

As feiras agroecológicas reúnem um conjunto de experiências exitosas que têm contribuído concretamente para os processos de adaptação e enfrentamento às dificuldades da região, tendo a Agricultura Familiar como principal produtora de alimentos, fator este que comprova o que Leão (2010) citou sobre a criação de espaços particulares, ou seja, as feiras agroecológicas, para a distribuição e venda destes produtos.

Frente a isto, o principal objetivo destas é levar as famílias a refletirem sobre o padrão de consumo alimentar a partir das experiências locais das feiras agroecológicas que combinam sustentabilidade ambiental, aumento na renda local e saúde para a população consumidora e, ainda, refletir sobre a sustentabilidade dos agrossistemas familiares em transição, estando este objetivo em harmonia com o que Barros (2010) mencionou relativamente à preocupação com a produção limpa de alimentos associada à aplicação de práticas de produção agrícola menos degradantes e com potencial de promover a preservação máxima dos recursos naturais.

Ademais, as feiras agroecológicas reforçam a necessidade de fortalecimento das experiências locais como estratégia para enfrentar as mudanças climáticas e o contexto político, por duas grandes razões:

(i) Primeiramente, porque em conformidade com pesquisas que têm sido realizadas em parceria com as ações do Centro Sabiá, comprova-se que a Agrofloresta é a agricultura do presente e do futuro, de baixo carbono, eficiente no combate à desertificação e na produção de alimentos sem veneno;

(ii) Segundamente, porque além da promoção da participação da juventude rural, destaca-se que estas feiras são resultado de um longo caminho de transformação, trilhado por pequenos produtores e produtoras rurais, tendo seu início histórico marcado pelo processo de transição do modelo de agricultura convencional para o modelo de agricultura agroecológica.

Através do Centro Sabiá, existem 23 espaços de feiras agroecológicas em Pernambuco, estando eles localizados no Recife (sete espaços); Olinda (um espaço); Zona da Mata Sul (seis espaços); Agreste (um espaço); Sertão do Pajeú (cinco 
espaços); e Sertão do Araripe (três espaços). A seguir, o Quadro 8 exibe as redes de articulação do Centro Sabiá, ou seja, os espaços onde é possível encontrar produtos agroecológicos no Sertão do Pajeú:

Quadro 8. Espaços de Feiras Agroecológicas na região do Sertão do Pajeú.

\begin{tabular}{|c|c|}
\hline \multicolumn{1}{|c|}{ REGIÃO } & \multicolumn{1}{c|}{ ESPAÇO DA FEIRA AGROEOCLÓGICA } \\
\hline & • Feira Agroecológica de Serra Talhada; \\
& • Feira Agroecológica de Afogados da Ingazeira; \\
SERTÃO DO PAJEÚ & • Feira Agroecológica de São José do Egito; \\
& • Feira Agroecológica de Tabira; \\
& • Feira Agroecológica de Tuparetama. \\
\hline
\end{tabular}

Fonte: Centro Sabiá (2018).

\section{Considerações Finais}

Para além da ação antrópica associada às dificuldades impostas pelas condições naturais da região, o Sertão do Pajeú tem sido palco de grandes lutas dos movimentos sociais e, nessa conjuntura, aspectos como o fortalecimento da sociedade civil, da mobilização, envolvimento e capacitação das famílias, são ações concretas que têm transformado a realidade dessa região, tanto no que se refere ao ambiente natural do território, quanto no que condiz à qualidade de vida da população que vive da agropecuária.

O modelo de agricultura implementado na região usa venenos, não tem preocupação com a saúde das pessoas, não ajuda a melhorar a qualidade de vida das famílias, só dá lucro aos grandes produtores e, notadamente, destrói gradualmente o meio ambiente e os recursos providos pelo mesmo. Não obstante, com um olhar fundamentado sobre os Programas pesquisados, foi possível assimilar que apesar da região do Sertão do Pajeú enfrentar tais problemáticas e dificuldades, mas quando existe o apoio e a capacitação para viabilizar uma produção sustentável na agricultura e, sendo esta, adaptada à realidade local, é possível transformar realidades e promover a melhoria da qualidade de vida.

Particularmente a este último aspecto, confirmou-se que através da produção agroecológica é possível criar condições melhores de vida, haja vista a disponibilidade diversificada de alimentos. E acrescenta-se essa conquista às feiras, sendo estas os principais espaços para comercialização da agricultura familiar e promoção da geração de renda, acima de tudo quando o sistema de produção é capaz de promover produtividade agrícola, melhorar a alimentação e diminuir as diferenças sociais.

Pôde-se concluir que, em um ambiente onde são frequentes os períodos longos de seca, como é a região do Sertão do Pajeú, as famílias agroecológicas precisam de oportunidades de melhoria para poderem se adaptar e conviver com as dificuldades. Mas, especialmente, enfatiza-se às considerações que existe um longo caminho de transformação, trilhado por pequenos produtores rurais, tendo seu início histórico marcado pelo processo de transição do modelo de agricultura convencional para o modelo de agricultura agroecológica.

Nesta trajetória, um conjunto de fatores relacionados aos aspectos ambientais e sociais, como articulação da sociedade civil organizada, oportunidades de aprendizagem e participação social, constatados nos Programas em ação, promovem uma resiliência sistêmica global. Por outras palavras, as famílias que adotam métodos agroecológicos têm a percepção de que são mais capazes de lidar com as dificuldades do Semiárido e, concomitantemente ao processo de desenvolvimento da produção agroecológica, melhoram a qualidade de suas vidas através do acesso ao conhecimento, a formação, a efetiva participação social e a inserção nos mercados locais, mas acima de tudo, passam a construir uma parcela de uma nova sociedade que faz a alocação e uso eficiente dos recursos naturais respeitando os limites de produção do meio ambiente.

Diante o que foi identificado a partir do caso do Centro Sabiá, propõe-se para futuros trabalhos a realização de estudos 
de caso em outras organizações não governamentais que também atuam a partir de Programas pautados em ações sustentáveis de agroecologia, a fim de que se possa apontar outros aspectos que também potencializam o acesso de pequenos produtores rurais a mercados locais e à geração de renda. A motivação desta sugestão justifica-se no fato de que quanto mais amplo for o conhecimento sobre o espaço e a população que ali reside, a ação de Programas poderá ser mais coerente e mais acertiva sobre as potencialidades e as dificuldades de uma região.

\section{Agradecimentos}

Em agradecimento ao Conselho Nacional de Desenvolvimento Científico e Tecnológico pela bolsa de estudos e ao Programa de Pós-Graduação em Engenharia e Gestão de Recursos Naturais, da Universidade Federal de Campina Grande. À Professora Dra. Isabel Lausanne Fontgalland por todos os ensinamentos transmitidos sobre Economia e Meio Ambiente e que inspiraram a forma de pensar, estudar e pesquisar a temática aqui apresentada. Ao Centro de Desenvolvimento Agroecológico Sabiá pelas entrevistas e material compartilhado da sua atuação no Sertão do Pajeú.

\section{Referências}

Assis, R. L. de. (2006). Desenvolvimento rural sustentável no Brasil: perspectivas a partir da integração de ações públicas e privadas com base na agroecologia. Revista Economia Aplicada, 10 (1). 10.1590/S1413-80502006000100005.

Aureliano, M. C. (2019). Agrofloresta produzindo alimentos saudáveis e esfriando o planeta: sistema de agricultura que avalia eficiência na produção de alimentos e fornecimento de serviços ambientais. Caderno Dois Dedos de Prosa: Qual o modelo de desenvolvimento que você defende para o planeta? (93). 8 11.

Barros Junior, G. (2010). Acervo de arquivos: implantação de Sistemas Agroflorestais Agroecológicos no Sertão do Pajeú, Semiárido.

Ferreira, A. P. L. (2016). Agricultoras do Pajeú: feminismo e agroecologia no semiárido brasileiro. Revista Pegada, 244-262. file://C:/Users/barba/Downloads/3916-15792-1-PB\%20(1).pdf.

Gil, A. C. (2008). Métodos e Técnicas da Pesquisa Social. (6a ed.). Atlas.

Guanziroli, C. E. \& Cardim, S. E. de S. C. (2000). Novo Retrato da Agricultura Familiar. O Brasil Redescoberto. Projeto de Cooperação Técnica INCRA/FAO. Brasília.

Instituto Brasileiro de Geografia e Estatistica - IBGE. (2006). Censo 2006: Resultados Preliminares.

Leão, E. L. de S. (2010). Evolução e situação atual da agricultura de base ecológica em Pernambuco. $-48^{\circ}$ Congresso Sociedade Brasileira de Economia, Administração e Sociologia Rural - Tecnologia, desenvolvimento e integração social.

Mattei, L. (2005). Impactos do PRONAF: Análise de indicadores. Ministério do Desenvolvimento Agrário. Núcleo de Estudos Agrários e Desenvolvimento Rural. Brasília.

Ortega, T. R. R. (2007). Agroecología y redes solidarias (Capital Social) - Maracajá, la búsqueda de un desarrollo sustentable en la región semiárida del Nordeste de Brasil. Tesis Doctoral en Agroecología, Sociología y Desarrollo Rural Sustentable. Instituto de Sociología y Estudios Campesinos. Escuela Técnica Superior de Ingenieros, Universidad de Córdoba-España.

Paranhos, M. G. F. (2007). A trajetória da Rede Ater Nordeste: construindo conhecimento agroecológico pelo Nordeste brasileiro. Construção do Conhecimento Agroecológico - Novos Papéis, Novas Identidades. Caderno do II Encontro Nacional de Agroecologia, pp. 56-70.

Pearce, D. (2002). An Intellectual History of Environmental Economics. Annu. Rev. Energy Environ. 57-81. 10.1146/annurev.energy.27.122001.083429.

Pereira A. S. et al. (2018). Metodologia da pesquisa científica. UAB/NTE/UFSM. https://repositorio.ufsm.br/bitstream/handle/1/15824/Lic_Computa cao_Metodologia-Pesquisa-Cientifica.pdf?sequence=1.

Pires, A. H. (2019). Água: bem comum e não mercadoria. Caderno Dois Dedos de Prosa: Qual o modelo de desenvolvimento que você defende para o planeta? (93), 03-04.

Ramos, P. (2007). Dimensões do Agronegócio Brasileiro - Políticas, Instituições e Perspectivas. Ministério do Desenvolvimento Agrário.

Tubino, N. (2013). Participação social na agricultura camponesa e na agroecologia - Da Carta Maior. III Encontro Nacional de Agroecologia, Rio 20, da Caravana Agroecológica do Apodi. Juazeiro-BA.

Vieira, P. F. (2019). A ética do ecodesenvolvimento na era do antropoceno: uma perspectiva econcêntrica-transdisciplinar. In: Philippi JR. (Coord.). Ética Socioambiental. Manole. 
Research, Society and Development, v. 10, n. 1, e47010111937, 2021

(CC BY 4.0) | ISSN 2525-3409 | DOI: http://dx.doi.org/10.33448/rsd-v10i1.11937

Weber, J. (1997). Gestão de recursos naturais renováveis: fundamentos teóricos de um programa de pesquisas. In: Vieira, P. F., Weber, J. (Org.) Gestão de Recursos Naturais Renováveis e Desenvolvimento: Novos Desafios para a Pesquisa Ambiental. Cortez. 